\title{
The Analysis of Influence Factors on Agricultural Population Transfer Living in the City_-Survey on the Migrant Workers in Nanjing
}

\author{
Xiaoting Tan ${ }^{1, a}$ and Guangsheng Zhang ${ }^{2, b^{*}}$ \\ ${ }^{1,2}$ Shenyang Agricultural University, Dongling Road NO.120, Shenhe District, Shenyang City, \\ Liaoning Province, China \\ atanxtsyau@163.com, bgshzhang@163.com \\ *The corresponding author
}

Keywords: Migrant workers; Settled in preference; Affecting factors; Agricultural population

\begin{abstract}
In order to know the movement of agricultural population that are willing to settle in urban cities, there are certain factors that affect them to live in the city, which are significant on promoting the urbanization process. This paper is based on the survey of migrant workers in Nanjing, a study on factors affecting their living trend. The Research uses probit model, through the empirical analysis, and analyzes the main factors influencing the will of individual who lives outside the labor city. Results show that the main factors affecting agricultural transfer of population are: labor culture level, gender, income, integrated into city life. The paper revealed the China's rural micro-foundation which have a great significance on promoting the development and process of urbanization.
\end{abstract}

\section{Introduction}

Promoting agricultural transfer of population into urban areas is the important prerequisite of achieving new urbanization in China [1]. Nowadays, although our country has a large number of labors moving from rural to urban cities, but only achieved a profession change from agricultural to non-agricultural industries, their place of residence remained in the countryside. From the micro level of the city, urbanization is made up of two aspects, one is peasant with less work experience and the second is residence. In other word, only when things are completed and ambulatory people settled in city can realize the transformation is achieved. So, transfer of agricultural population whether have the will to stay or leave the city, the judgment depends on the factors which have significance important on city development, their decision making factors is of great significance for pushing forward the process of urbanization.

"Push and pull" theory that exist in immigration and emigration have some factors, the factors of "push" in the movement of population, and also a "pull" factors of migration. "Push" and "pull" not only includes the objective factors like economy, culture, but also include the subjective psychological factors.

In the case of the household registration system reform, agricultural population transfer and other discrimination, which affect their willingness to live, should be put to further study. In this paper, the key to the discrimination and analysis on the degree of a relation between the city of quantitative model, Nanjing migrants labor to the agriculture transfer population under the 2013 field survey questionnaire, analyzes the main factors affecting the will of an individual migrant workers settled in the cities, revealed the China's rural micro-foundation which have a great significance on promoting the development and process of urbanization.

\section{Research Model.}

According to the migration cost-benefit theory, a person's age, gender, marital status, cultural level, whether has the skill and past experience may affect the movement from one region to another[2-3]. The decision-making behavior of immigrants; the "prospective migrants" of foreign labor income level, level of discrimination and the length of working time, on whether could be possible to 
officially settled in the city, all this factors tend to have a great impact on migration[4-6]. After moving the rural labor force into the town, the social network might still be limited to the rural inhabitants, so it is difficult to adapt to urban life truly. And as becoming urban residents, the main achievement is to stay settled, which is one of the important factors affecting the migrants[7-8]. Therefore, this article will mainly focus on the settling of the urban contacts that have a great influence on leaving the city. Based on the above analysis, the following aspects might be the main factors affecting the migrant worker's settling down and staying in the city.

The Age and Cultural Education Level. Due to young people moving into the area of work than older people and the length of the service they will provide, it is expected to receive a large amount of migration gains, thus by making it easier to make migration decisions. But age and migrants workers may not be a simple linear relationship between willingness to settle, because in the transfer of older people, some are willing to spent a long time working in the city, while some are reluctance to settle down, gradually returned, exit the progression of the transfer.

Level of education also has a great impact on making decision. Generally, people with higher level of education tends to have higher rates, because they have more choice, expectations of future returns is also high; similarly, high level education make people's ability to accept new things relatively strong, easier to adapt to the new challenges in the urban life, and thus making it more likely to seek changes in lifestyle, the city greater risk.

The Income Level and Time in the City. The higher income level, the agricultural works and the transport of people to the city is to seek a stronger ability to survive and develop in the city through higher incomes level from the industrial base occupations. It can be therefore, income level and cost of living in urban areas are extremely related. That is, the higher the income level the greater the possibility of people to settle down and live in the city. Conversely, the lower the income level the less chance of people to settle in the city. Besides, higher income earners have greater life satisfaction than low-income earners. For cities, time is needed both by authorities and the people for the arrangement that will allow people to settle down conveniently in the cities.

Communicating between City People and Discrimination. For the transfer of rural labor force to enter the town, the migrants requires a strong ability to adapt to the new life, such as cultural values, lifestyle and gained recognition psychologically, emotionally to find a home. Psychological adaptation is the transfer of agricultural population to adapt to the highest level of population. This kind of psychological adaptation which may directly reflect in their understanding of town is true, harmonious relationship with town and so on. Interaction with town people is the main objective of agricultural transfer of population to adapt into the town, which in turn validates the major aspect of this paper. In addition, migrant workers often encountered some prejudice, discrimination, suffering from urban residents, due to the lack of status in daily life and social activities. All these problems and discriminations are the main issues that make it difficult for them to associate and have normal relations with city people, and also make it less possible to have place into the urban social groups, which may have a huge negative significance affecting the settlement.

\section{Empirical Analyses}

Data Source. In this paper, the sample data is collected from part of a random survey of migrant workers conducted on 2013 in Nanjing, Jiangsu province. The main purpose of the survey is to examine the factors affecting the migrant worker's settling down in the city. Personal investigation include migrant behavior, family, economic situation, living condition, personal assessment and the willingness to settle down in the city and so in. The survey received a total of 284 questionnaires; get a total of 250 effective samples after eliminating the invalid sample data.

The Empirical Model. Due to the dependent variable of this research "foreign labor force" that are willing to settle down in the city, 0 , and 1 , are selected as binary variables, just as selected by James McFadden (D. Mcfadden) based on utility theory and theory of basis for the estimated Probit model for analysis[9]. Thus:

$$
Y^{*}=\beta_{0}+\beta X+e,\left[Y=1 \text {, when } Y^{*}>0 ; e 1 s e Y=0\right]
$$


$\mathrm{Y}^{*}$ is an unobservable latent variable.

Assuming that $\mathrm{e}$ is independent of $\mathrm{x}$, and obey standard normal distribution.

Assuming that the first Labor decided whether to settle in city, by a direct observation, the unobservable utility index $\mathrm{Y}^{*}$ (the difference between potential level of settlement and nonsettlement decision), the utility index is decided by the explanatory variable $\mathrm{x}$. $\mathrm{Y}=1$, suppose a first migrant labor decided to settle, in which $\left(Y^{*}>0\right)$ and later the migrant labor choose not settle down anymore, that is $\mathrm{Y}=0$ and $\left(\mathrm{Y}^{*}<0\right)$. Therefore, based on the above assumptions, the effects that cause migrants to leave or settle in the city depend on the binary discrete choice and the model can be represented as:

$$
\begin{aligned}
& \operatorname{Pr} o b(Y=1 \mid X=X)=\operatorname{Pr} o b\left(Y^{*}>0 \mid X\right)=\operatorname{Pr} o b\left[\left.\left(e>-\left(\beta_{0}+\beta_{X}\right)\right)\right|_{X}\right] \\
& =1-\Phi\left[-\left(\beta_{0}+\beta_{X}\right)\right]=\Phi\left(\beta_{0}+\beta_{X}\right)
\end{aligned}
$$

Where $\Phi$ is the standard normal cumulative distribution function.

Due to economic interpretation of binary response the model of regression coefficient is difficult, therefore, it is estimated that the little changes on the selected probability of each variable in the marginal effect, the effect is more reasonable in the interpretation of the regression coefficient (Greene, 1993). The marginal effect of each variable is given below.

$$
\frac{\Delta \hat{P}\left(Y=\left.1\right|_{X}\right)}{\Delta X_{j}}=g\left(\hat{\beta}_{0}+\hat{\beta}_{j} x\right) * \hat{\beta}_{j}
$$

Where, $g(\bullet)$ is the standard normal distribution density function . $\hat{\boldsymbol{\beta}}_{j}$ is the estimated parameters.

Basic Descriptive Statistics. Among the 250 valid questionnaires, a total of 129 people are willing to settle in the city, and a total of 121 people are not willing to settle in the city. Among the number of those that are willing to settle in the city, they represent the $51.6 \%$ of migrants labor. The study selected the willingness to stay as the dependent variable, explain its significance importance in the Table 1 below.

Table 1 Variable selection, expected direction and basic descriptive statistics

\begin{tabular}{lllll}
\hline $\begin{array}{l}\text { Variable } \\
\text { name }\end{array}$ & Meaning & $\begin{array}{l}\text { Expected } \\
\text { direction }\end{array}$ & Average & $\begin{array}{l}\text { Standard } \\
\text { devitiaon }\end{array}$ \\
\hline Age & Age & + & 35.09 & 9.93 \\
Age $^{2}$ & Age squared & - & 1329.69 & 779.03 \\
Edu & Education level & + & 2.76 & 0.985 \\
Gender & $(1=$ has not been to school, 5= College $)$ & $?$ & 0.728 & 0.446 \\
Hukou & Sex $(1=$ male, $0=$ female $)$ & $?$ & 0.816 & 0.388 \\
Leader & Accounts $(1=$ agricultural, $0=$ non-agricultural $)$ & $?$ & 0.180 & 0.385 \\
Tech & Marital status $(1=$ maiden, $0=$ married $)$ & $?$ & 0.18 & 0.385 \\
Income & Worked as a cadre $(1=$ is, $0=$ no & + & 0.416 & 0.494 \\
Citizen & Control technology $(1=$ is, $0=$ no) & + & 2.602 & 1.295 \\
Discr & Whether discriminate $(1=y e s, 0=$ no $)$ & + & 4.344 & 2.262 \\
\hline
\end{tabular}

Data source: based on the collected data from 2013 surveying.

\section{Results Analysis and Discussion}

Table 2 shows the main empirical results of the model, it can be seen that the overall results of the model regression is likelihood the ratio of 77.51, and statistical significance of $1 \%$. 
Table 2 Willingness of migrant labor to settle and Probit model estimation

\begin{tabular}{llll}
\hline Variable & $\begin{array}{l}\text { Number of regression } \\
\text { line }\end{array}$ & Standard error & Marginal probability \\
\hline & 0.0439 & 0.0552 & 0.0079 \\
Age2 & -0.0003 & 0.0006 & -0.0001 \\
Gender & $-0.7671^{* *}$ & 0.2167 & -0.2934 \\
Hukou & 0.2825 & 0.2521 & 0.1136 \\
Marry & 0.0515 & 0.3205 & 0.0064 \\
Leader & -0.2078 & 0.3527 & -0.0827 \\
Edu & $0.5246^{* *}$ & 0.1130 & 0.2089 \\
Tech & -0.2352 & 0.1937 & -0.0923 \\
City year & $0.2450^{* *}$ & 0.0804 & 0.0975 \\
Income & $0.1220^{* *}$ & 0.0443 & 0.0494 \\
Citizen & $-0.2917^{*}$ & 0.1215 & -0.1167 \\
Discr & -0.1460 & 0.1828 & -0.0581 \\
Constant term & -2.6398 & 1.2010 & \\
Log likelihood $=-133.74$ & LR chi2 $(13)=77.51^{* *}$ Pseudo R2 $=0.2247$ & \\
\hline Note: $* *$ is the stistical & significe at $5 \%$ and $1 \%$ level respectively.
\end{tabular}

Note: $* * *$ is the statistical significance at $5 \%$ and $1 \%$ level respectively.

Data source: calculation study of 2013.

As predicted, the time in the city, close relationship with city, will produce a positive effect on migrants labor willingness to settle in the cities, with statistical significance of $1 \%$ and $5 \%$ level respectively. This shows that the longer the time in the city, more on social life of the urban inhabitants which will increasingly be high, the easier it make them to adapt and accept the new life and changes in the city. And thus in turn, brings about a high possibility and willingness of people to settle down. The marginal probability indicates that urban life increase highly for every year, and thus increases the probability to about $9.74 \%$. The lack of close relationship with city also makes it more difficult to settle. There is no significant effect on the variable on whether the discrimination by city inhabitants against the migrant workers, but the relationship between the two may grow negatively high on whether to settle in the city, and namely when there is a high discrimination there will be less willingness to settle.

Wage income in the city is also one of the main key factors on determining the migrant workers desire to settle in the cities. The variable is statistically significant at $1 \%$ level, this shows that the higher the monthly income, the higher the probability of migrant workers choose to settle. The higher marginal probability indicates that with respect to low-income people, the percentage of high-income earners that are willing to stay in the city will increase to about $4.85 \%$.

Migrant workers have their own labor power such as, cultural degree level of education and whether to settle in city have a positive relation, and whether can have access to advanced technology, whether a migrant workers work as a cadre and their willingness to settle has a negative correlation relationship between. This shows that the higher the level of cultural education degree of the migrant workers and their tendency to settle in the city, have access to the advanced technology and worked as a cadre, the more the rural migrant workers choose not to settle in city. But only the effect of cultural degree on this role of the city will have statistical significance at $1 \%$ level.

The role of age of migrant workers to settle in city is consistent with our basic assumptions: the age and age squared role in the settling down were positive and negative respectively, the probability of young labor force choose to settle is increasingly high, and as they grow older, their overdrafts like the young body, will become unbearable due to the high labor intensity and psychological burdens. Therefore, the desire to settle in the city will gradually diminish. Empirical results shows that male labor forces relative to the women in the workforce are more likely choose not settle in the city. Unmarried workers compared with married ones are less likely to choose settling in the city, which can reflect the life of the new generation of young labor force. 


\section{Conclusions}

First of all, the lack of migrant's workers social capital is the main reason that impede them to assimilate into the town. The more compatible their relationship with local residents is the greater enthusiasm for the migrant workers to stay and settle in the city. Therefore, in working towards the discrimination against city workers by urban residents, is to improve and raise social capital investment and make it incentives to the city workers. This is to change the process of industrialization in China into the city farmers "flow without turn" .

Secondly, the economic factors are also among the main factors restricting agricultural transfer of population. This research surveys data which shows that the migrant workers were participated in work-related insurance, medical insurance, pension insurance and other safeguards that still remain at low level. By the proportion, it can be expected that the social security system will gradually be improved, which will increase the possibility of migrant workers to stay and settle in the city.

Thirdly, cultural degree level of education has long been considered as the one of the factors affecting agricultural transfer of population. It can be seen in this paper that the higher the degree of cultural level of education of the migrant workers to adapt better to the urban life, higher ability and willingness to stay in the city. Therefore, the government should increase the intensity of education including all kinds of job-training that will benefit more to the community.

\section{Acknowledgements}

Supported by China Postdoctoral Science Foundation (2013M540235), Science Foundation of Ministry of Education of China (13YJC790129), Foundation of Liaoning Educational Committee (w2015335).

\section{References}

[1] John Knight, Ramani Gunatilaka, Great Expectations? The Subjective Well-being of Rural Urban Migrant in China, World Development, Vol. 1(2010), p. 113-124.

[2] Becker, G.S., A Theory of the Allocation of Time, Economic Journal, Vol. 75(1965), p.493-517.

[3] Erin Strumpf, Medicaid's Effect on Single Women's Labor Supply: Evidence from the Introduction of Medicaid, Journal of Health Economics(2011), Working Papers.

[4] Gendell, Murray, Older Workers: Increasing Their Labor Force Participation and Hours of Work, Monthly Labor Review, Vol. 131(2008) No. 4.

[5] Blau, Gilleskie, Health Insurance and Retirement of married Couples, Journal of Applied Econometrics, Vol. 21(2006) No.7, p.935-953

[6] Dahlberg, M. , M. Eklof, P. Fredriksson, J. Jofre-Monseny, Estimating Preferences for Local Public Services Using Migration Data, Urban Studies, Vol.49(2012) No.2, p.319-336.

[7] Diamond R. , The Determinants and Welfare Implications of US Workers' Diverging Location Choices by Skill: 1980-2000, Job Market Paper.

[8] Sylvie Démurger, Marc Gurgand, Shi Li, Ximing Yue, Migrants as Second-class Works in Urban China? A Decomposition Analysis, Journal of Comparative Economics, Vol. 37(2009) No. 4, p. 610-628.

[9] D Mcfadden, R Engle, Handbook of Econometrics, Elsevier, 1986.

[10]Meng, X. , K. Shen, and S. Xue, Economic Reform, Education Expansion, and Earnings Inequality for Urban Males in China, 1988-2009, Journal of Comparative Economics, Vol.41(2013), p.227-244. 